\title{
Sports Marketing Strategy Research of China Enterprise
}

\author{
Zhe Luo ${ }^{1, a}$, Lei Li ${ }^{1, *}$ \\ ${ }^{1}$ Yunnan College of Business Management, Kunming, Yunnan Province, China \\ a31517615@qq.coom \\ *Corresponding author
}

Keywords:Sports marketing,Enterprise, Strategy and Research

\begin{abstract}
The sports industry is in the rapid economic development, the national fitness concept deeply rooted in post-Olympic era has broad development prospects. This article is mainly from the mode of sports marketing, analyzing the present situation and problems of China's sports marketing, sports marketing strategy for the enterprise of China to point out the development of sports marketing strategy.
\end{abstract}

\section{Introduction}

In the contemporary context of the national economy booming, the development of the sports industry is rapid. Currently, in the sports marketing business marketing programs showed the proportion of explosive growth, the development of the sports industry, including the country's economic development has provided great impetus [1]. However, with the international sports marketing to mature than the Chinese sports marketing still somewhat immature, there are many shortcomings. In order to achieve the healthy development of sports marketing and sports marketing to achieve innovation, the need for the status quo of Sports Marketing a comprehensive grasp, and find out the problems, which made recommendations for strategic planning and development of sports marketing.

\section{The value of sports marketing and mode}

Sports marketing connotation. "Sports marketing" namely enterprise through physical, financial and other means, with sports organizations, activities and projects to establish a link, right, right to obtain corresponding name, then use advertising, public relations, sales promotion, brand positioning, integration, set up the unique brand association and brand recognition, purposefully promote the implementation of marketing strategy. It has two forms: the marketing of sports itself and "through" sports marketing.

Sports marketing have a long-term, systematic and cultural characteristic. The real implementation of sports marketing company sales is not a product, but a kind of culture, a kind of for sports resonate with consumers deep cultural identity. In a nutshell, sports marketing have the following several characteristics [1]: a. charisma is strong, easy to accept, good publicity effect (an empirical survey from the United States, 64\% of respondents are willing to buy sports sponsorship manufacturer's products. Coca-Cola Beverage Company $38 \%$ of the world's consumers to buy its main reason is that Coca-Cola is an Olympic designated drink). b.Wide audience, pertinence. c. public welfare, health up d. small controllability, substantial investment risk big.

The use of sports marketing value. Modern enterprise use all kinds of sports marketing model to sports organizations, sports events, sports stars as the medium to its products and love sports linked to target consumers, through a series of sports marketing activities make its brand is deeply rooted in the hearts of the people, enhance its brand awareness and market competitiveness, and further open the market, gain more market share [2]. The role of sports marketing mainly has the following points: first, the enterprise to carry on the sports marketing, can improve the enterprise and brand reputation and popularity, and thus enhance the brand value. Second, sports marketing are a kind of cultural marketing and public marketing, establish a good image for the enterprise [2]. And enterprise can 
through the sports marketing greatly improve the sales of enterprises, to gain substantial profits. Also, sports marketing are helpful to create a good corporate culture, improve staff quality and morale. At the beginning of this, the sports marketing has produced wider sports fan, cultivate the market.

The marketing pattern of sports marketing. The diversification of modern enterprise sports marketing mode, commercial derived from the 1984 Olympics in Los Angeles. More common forms of sports marketing include: exclusive sponsor or participate in organizing sports events, field sales or specify products and cooperate with sports media, sports star endorsements and implicit marketing or a lift.

a. Sponsor or participate in sports organization. Sports sponsorship is the enterprise to a certain assets, including sports games, sports organizations, sports teams or elite athletes pay a certain amount of cash or in-kind, to support and help, and as the physical assets of the partners involved in developing sports market related to the physical assets, so as to achieve enterprise marketing goals of a particular kind of commercial behavior.

With the help of successful sponsorship activity in and around the sponsorship for a series of marketing activities, the enterprise besides can get a lot of publicity exposure, also can let the enterprise to support the form of sports activities, enterprises will obtain a good social effect so as to improve brand awareness, create a more favorable development environment for the enterprise [3]. Examples of corporate sponsorship of sports events in the life is the most common, such as Samsung and VISA, many excellent brand directly with the aid of the Olympic Games, World Cup and other international large-scale events to promote enterprise, improve enterprise visibility and reputation and by constantly to the world of sports sponsorship.

b. Exclusive field sales or designated products. Exclusive field get exclusive rights to be sponsors in sports exclusive rights of their products, is a specialized event organizers to sponsor rights and interests. Part such as the Beijing Olympic Games, drinks only provide drinks Coca-Cola company subordinate brand, competition venues in the brush calorie of consumption is limited to use VISA card payments [3]. Although such restrictive consumption greatly constrained the audience's option, may cause the resistance of one part person, but after all sponsors for the Olympic Games smoothly investment of manpower and capital contribution is obvious, therefore from increase brand exposure and increasing the brand returns in terms of profitability, the audience is accepted and approved.

c. Cooperate with sports media. Cooperate with all kinds of influential sports media is also a kind of indirect form of sports marketing [4]. Famous sports media both at home and abroad have some competition for sports fans show broadcast or all kinds of wonderful interactive sports entertainment. TV media, such as CCTV sports channel is a representative of the domestic sports media, print media Titan sports, sports media have notecase sports channel, etc. These sports media has tremendous influence in sports enthusiasts. CCTV sports channel broadcast perennial European football league, the NBA and other top competitions around the world, there are some people happy features of the program, such as the world football, basketball, park, etc.; Sports weekly snare a rich sports information, people become the habit of reading the newspaper choose; And network, such as notecase sports media in addition to provide the most timely action and sports news, it is a huge physical database, is an indispensable tool for sports fans.

Now, many enterprises choose different forms of cooperation with the sports media, LiNing named to undertake, such as notecase sports channel Sohu sports channel's cooperation with Adidas, Nike, and named sina sports channel. They often targeted to participate in the programmer, or of some potential customers interested in interactive activities, and have achieved good promotion effect.

d. Sports star endorsements. Through sports celebrity endorsements products and brands is one of the more common forms of sports marketing. Companies employ suitable for its own brand of sports stars as spokesperson for corporate brand, in the propaganda with the aid of sports stars' influence to attract the attention of consumers so as to achieve better brand promotion and propaganda effect.

Companies are looking for the brand spokesperson, tend to choose those positive, positive and influential, known as the target market, development, rise in his career, also should as far as possible is the only one brand and product of sports figures [4]. Good athletes often can get the best identity in 
public, thus in emotional businesses and consumers will be tightly linked together. Sports star has been a focus of the audience even object of worship, so by brands, consumers will place for sports stars emotional well onto the brand so as to effectively enhance the brand loyalty and reputation. According to statistics, it is about a quarter of advertising to use sports celebrity spokesperson. Especially for Chinese people, they are relatively more attention to sports stars, so the sports stars also are the life of the sports marketing.

\section{Chinese enterprises to carry out sports marketing strategy analysis}

Market segmentation, choose target market. Market segmentation refers to the enterprise according to the different market segmentation variables be divided into different customer groups. In the market, due to the effect of many factors, different consumers generally have different desires and needs, thus different consumers have different buying habits and purchasing behavior [5]. Because of this, the enterprise marketing personnel can according to these factors in the whole market segmentation for a number of different market segments. Each child market is a similar need of consumers. Due to these child consumers have similar needs of the market, the enterprise through market research and analysis to be able to find these specific people's interests, lifestyle, entertainment, and value orientation, and to determine the targeted marketing.

Accurate positioning, brand connotation. After selected the target market, enterprises need to provided by the product in the target market customers mind what kind of position to make a decision, namely in terms of product market positioning, so that enterprises in developing marketing strategy especially when preaching of advertising can highlight the enterprise product market positioning, in order to attract the corresponding target customers [5].

Enterprise in the specific implementation of sports marketing, should find the theme of the public to accept the breakthrough point, from the business promotion expresses the humanistic concern to the public. It is also the spiritual needs of a meet to the public. And, more importantly, firms that sponsored events such as Olympic Games conveys the humanistic spirit should bring added value to enterprise brand, the brand and asked to produce a positive contact sports, sports culture and brand culture and corporate culture, thus cause the resonance of the consumers and businesses, in consumers' mind to form long-term preference, become a competitive advantage of the enterprise. Such enterprises can truly reflect the value of sports marketing, to continue to grow stronger, survival ability and sports virtually enhance and extend the brand value.

Formulate reasonable marketing budget.Eventually determine whether in the enterprise to participate in a sporting event, the enterprise must fully consider the factors such as capital reserves, financing ability, investment plan.

This is because companies often spend huge sums of money to sponsor sports teams or events we can secure protocol, and the cost of the development of sponsorship will be more. If sponsorship money outside of the marketing budget is insufficient, enterprise can't effective use for sponsorship, then lost the real marketing opportunities [6]. Therefore, the enterprise should be more, don't put the sports marketing as a game of "burn money". Foreign mature enterprises in received the invitation to a sports sponsorship letter, if the enterprise marketing budget in lack of money sponsorship of the sponsoring sports activities after more than five times, generally they will consider refused to sponsor. Because they know that desperate action will eventually make the enterprise into a financial crisis.

Using the concept of integrated marketing in sports marketing.Integrated marketing refers to the enterprise all marketing and communications activities, such as advertising, sales promotion, public relations, journalism, direct marketing, packaging, product development to reorganize, unified integration to interest relationship from different information sources on a particular brand of consistent information, in order to enhance brand appeal of consistency and integrity, unified configuration of information resources, unified use, improve the utilization rate of resources [6].

Here, integration has three meanings [4]: First, the enterprise needs to integrate different marketing communication tools, not only at a certain brand communication medium, but to the combination of target consumer, contact point to television, newspapers, magazines, outdoor media, the Internet communication tools such as optimizing combination; Secondly, the enterprises in the 
marketing communication, need a unified image, unified spread slogan; Again, need to develop different at different time points, the spread of preheated before, at the spread of matter, after the fact to consolidate. About the sports marketing, Coca-Cola has a classic joke: "in this article, the only need to follow a simple philosophy. If it is moving, sponsored it; if it is static, it painted red and brush on the Coca-Cola logo." Can be seen from here in this paper, the coke on sports marketing of continuity and integration of resources.

Do sports marketing planning for a long time. Brand not cast a day, it is need to insist for a long time, through the accumulation of time and time again. Long-term investment, sports marketing need money as much as possible to control the project, making it and the integration of its own brand [7]. Such as Coca Cola, it's contract with FIFA was in 100. Because only continuity, systematization of sports marketing strategy can make the product brand thorough popular feeling gradually and strengthen customer loyalty.

Throughout the domestic and foreign sports marketing model of market brand example of success, no not insist for a long time to the result of sports marketing [7]. Kodak company as early as in the Paris games in 1908, provided free of charge to the reporter of film, is the spread of the Olympic Games in the history of the earliest emergence of top brands; Since the 1988 Seoul Olympics began, the sustainability of samsung companies share the Olympic sponsorship activities, made the shot from low-end brand for the top brand of legend. Only with a long-term perspective enterprises can succeed in sports marketing competitive stage.

\section{Summary}

Through the analysis of the front, this paper holds that Chinese enterprises to develop sports marketing, you must change the idea, cannot like sports marketing is a kind of simple promotional activities, and should put it into the brand long-term development strategy, to make long-term investment plan. Second, to innovate marketing tools, the use of the concept of integrated marketing, caused a stir in the market, increase brand awareness. In addition, when choosing a sports event or sports star must be clear, they affect the groups and their products of the target audience are consistent, related to whether the own brand attributes. Finally need to get the budget of the investment, in determining the return under the condition of cost-effective, ensure that investment. Sports marketing is a complicated system engineering, so in front of the temptation of sports marketing, Chinese enterprises must think carefully, absolutely cannot be directly clappers sponsored sports activities.

\section{References}

[1] Q.Y. He, J. Yu, Sports and the relationship between marketing and brand strategy, Enterprise economy, vol.11, pp.21-26, 2014.

[2] D.H. Huang, Study on the relationship between the sports marketing and brand strategy, Market modernization, vol.1, pp.16-21, 2007.

[3] J.N. Zhang, Action mechanism and application of sports marketing mode choice, Sports journal, vol.34, pp. 54-59, 2006.

[4] W.G. Chen, VISA skill fully by the Olympic marketing, Management and wealth, vol.8, 09-13, 2003.

[5] Zh.Y. Cai, Analyses the application of sports sponsorship marketing strategy in the enterprise, Market modernization, vol.29, pp.80-85, 2005.

[6] J.T. Chen, Sports marketing is not only the sponsorship, Patrika, vol.9, pp.10-15, 2006.

[7] X.Q. Sun, Sports sponsorship marketing: integration view, Journal of Yunnan institute of finance and trade, vol.3, 43-48, 2013. 